\title{
BMJ Open HIV risk and pre-exposure prophylaxis interest among female bar workers in Dar es Salaam: cross-sectional survey
}

\author{
Guy Harling, ${ }^{\oplus 1,2,3}$ Aisa Muya, ${ }^{4}$ Katrina F Ortblad, ${ }^{5}$ Irene Mashasi, ${ }^{4}$ Peter Dambach, ${ }^{6}$ \\ Nzovu Ulenga, ${ }^{4}$ Dale Barnhart, ${ }^{2}$ Eric Mboggo, ${ }^{4}$ Catherine E Oldenburg, ${ }^{7,8}$ \\ Till Bärnighausen, ${ }^{3,6,9}$ Donna Spiegelman ${ }^{2,9,10,11,12}$
}

To cite: Harling G, Muya A, Ortblad KF, et al. HIV risk and pre-exposure prophylaxis interest among female bar workers in Dar es Salaam: crosssectional survey. BMJ Open 2019;9:e023272. doi:10.1136/ bmjopen-2018-023272

- Prepublication history and additional material for this paper are available online. To view these files, please visit the journal online (http://dx.doi org/10.1136/bmjopen-2018023272).

Received 2 April 2018

Accepted 31 January 2019

Check for updates

(C) Author(s) (or their employer(s)) 2019. Re-use permitted under CC BY-NC. No commercial re-use. See rights and permissions. Published by BMJ.

For numbered affiliations see end of article.

Correspondence to

Dr Guy Harling;

g.harling@ucl.ac.uk

\section{ABSTRACT}

Objective Female bar workers (FBW) in East Africa often conduct sex work to supplement their incomes, and may be vulnerable to HIV acquisition. Pre-exposure prophylaxis (PrEP) offers protection against HIV acquisition. However, there is little research on FBW's sexual health. Our objective was to determine HIV risk behaviours and interest in PrEP among FBW in the largest city in East Africa.

Design Cross-sectional survey covering respondents' work and personal lives, including social and behavioural risk factors for HIV. The survey aimed to determine the feasibility of working with FBW and HIV prevalence estimates. Those who did not report being HIV positive were asked about their knowledge of and interest in PrEP. All women were offered free on-site HIV testing and counselling (HTC).

Setting Eight randomly selected workplaces, that is, bars, in Kinondoni district, Dar es Salaam (DSM).

Participants 66 FBW ( $\geq 18$ years) selected at random from all women working in selected bars on the day of visit. Results Half of respondents reported having had sex for money: $20 \%$ with bar clients only, $15 \%$ with other men only and $15 \%$ with both. Almost all $(98 \%)$ reported $\geq 1$ non-commercial partners in the past 12 months; only $30 \%$ reported using condoms with these partners. $85 \%$ of respondents had ever been pregnant; $44 \%$ had had an unintended pregnancy. Only $5 \%$ of respondents had ever heard of PrEP. However, 54\% were somewhat/very interested in daily-pill PrEP and 79\% were somewhat/ very interested in long-acting injectable PrEP. When asked to rank modalities, long-acting injectable PrEP was the most preferred. Seven per cent of the 56 respondents who completed HTC tested HIV positive.

Conclusions FBW in DSM have elevated risk factors for HIV acquisition, and PrEP appears highly acceptable. Studies developing PrEP delivery models and assessing PrEP initiation and adherence in FBW appear warranted.

\section{INTRODUCTION}

Female sex workers (FSW), that is, women who receive money or other goods in exchange for sexual services, are a key population for the HIV epidemic in sub-Saharan Africa (SSA). These women are at especially

\section{Strengths and limitations of this study}

- The study population was selected at random from among all female bar workers in one of the three districts of the city of Dar es Salaam.

- HIV serostatus was evaluated using a rapid diagnostic test to avoid differential or non-differential misreporting.

- The sample is relatively small, potentially limiting power to see significant differences within subgroups, but can potentially motivate for studies designing and evaluating PrEP delivery models in this population.

- The sensitive nature of many of the HIV risk factors considered, and the self-report methods employed by the survey, may have led to under-reporting of risk behaviours.

- It is unclear how far the findings of this work can be generalised geographically.

high risk of acquiring and transmitting HIV and other sexually transmitted infections (STI). ${ }^{1}$ There is substantial research on how sex workers (SW) contribute to, ${ }^{2}$ and are impacted by, ${ }^{3}$ the HIV epidemic in SSA.

SW are sometimes divided into 'direct' SW for whom it is a primary profession, and 'indirect' SW, for whom it is a supplementary source of income. ${ }^{4}$ Indirect SW may be particularly important for HIV epidemics if they do not self-identify as SW, and thus are not reached by or do not access HIV prevention services such as those targeting direct FSW. In East Africa, female bar workers (FBW), women who either sell or deliver drinks to customers in commercial establishments, often act as indirect FSW.

FBW, or barmaids, often do not self-identify as $\mathrm{FSW}^{56}{ }^{6}$ and, in contrast to bar-based direct FSW, are employed by bars to provide non-sexual services. However, past quantitative research has shown that a substantial minority of FBW $(35 \%-45 \%)$ have sex in return for money, often with bar clients. 78 
FBW are often stigmatised and considered by others to be FSW. ${ }^{910}$ Qualitative work suggests that FBW have limited ability to protect themselves against STIs and other adverse consequences of sex work, notably when negotiating condom use. ${ }^{11-13}$ While precise numbers are hard to obtain, FBW likely comprise a large proportion of the 'accommodation and food service activities' employment category, which accounted for $6.5 \%$ of all employed Tanzanian women aged $>15$ in $2014,{ }^{14}$ and it has been claimed that FBW are the largest single employment group in Tanzania. ${ }^{15}$

There is substantial evidence-both direct and indirect-for structural, behavioural and biomedical interventions that should be able to reduce HIV acquisition and transmission among FSW. ${ }^{16}$ Structural approaches include community mobilisation, advocacy and social and economic empowerment alongside antidiscrimination policies including legal protection. Behavioural approaches include peer and community-based behaviour change, condom provision. However, many of these interventions are highly context specific and have proven difficult to implement consistently. ${ }^{17}$ Biomedical interventions may be more easily implemented in a wide range of settings. Proven biomedical approaches for FSW include FSW-friendly provision of services such as voluntary testing, linkage to care and antiretroviral treatment-including prevention of mother-to-child transmission and postexposure prophylaxis. There is no evidence at present as to how FSW-applicable interventions affect FBW.

Pre-exposure prophylaxis (PrEP) is an important biomedical HIV prevention tool, proven to substantially prevent HIV acquisition when taken as prescribed. ${ }^{18} 19$ There are several planned and ongoing PrEP demonstration projects in Africa. ${ }^{21}{ }^{21}$ However, previous PrEP studies have found variable adherence. ${ }^{22}$ Few PrEP trials have explicitly included FSW in their inclusion criteriaalthough some included proportions of unmarried women with multiple partners who reported histories of transactional $\operatorname{sex}^{16}$ - and to our knowledge none have targeted FBW. Evidence from FSW from South Africa, ${ }^{23}$ Kenya ${ }^{24}$ and Zimbabwe ${ }^{25}$ points to variable levels of uptake but rapidly declining retention of FSW on daily pill-based PrEP. Most published PrEP studies have focused on daily pill-based PrEP, although one study showed effectiveness for on-demand pills among men who have sex with men. ${ }^{26}$ However, other prevention modalities have been considered, including long-acting injectables, ${ }^{27} 28$ vaginal gels $^{29}$ and vaginal rings. ${ }^{30}$

WHO recommends PrEP for populations with an annual risk of HIV acquisition greater than $3 \%,{ }^{31}$ and as such it is likely to be a key intervention for reducing HIV among FSW internationally. ${ }^{32}$ Several countries in Africa with generalised epidemics have included FSW among the key populations eligible for PrEP, ${ }^{33-35}$ but few if any had begun widespread implementation for FSW by mid-2017. Past research has shown high acceptability of daily-pill PrEP among FSW hypothetically in a range of settings, ${ }^{36}$ and in practice in Kenya. ${ }^{37}$ While FBW acquisition risk may be lower on average than direct SW, it may well be that they meet the WHO criterion for PrEP.

At the time of this study, PrEP was not available anywhere within Tanzania. Two assessments of interest and barriers to PrEP among adolescent girls and young women were conducted in 2017 and found high interest but concerns around cost, side-effects and stigma. ${ }^{38}$ As part of one of these studies, healthcare providers were found to be largely supportive of PrEP provision, although they were concerned about behavioural disinhibition and work overload. ${ }^{40}$ Evidence specifically on FSW is not currently available.

Although many FBW also act as FSW, there is limited evidence on how much risky sexual behaviour FBW engage in. To our knowledge, there is no research on the acceptability of PrEP among FBW. We therefore analysed data from a feasibility study measuring HIV prevalence, HIV-related risk factors and initial interest in and acceptability of PrEP among FBW in Dar es Salaam municipality (DSM), Tanzania, the largest city in eastern Africa.

\section{METHODS}

We conducted a cross-sectional study using a two-stage sampling method in January 2017. This study was a feasibility study whose primary aim was to determine the feasibility of working with FBW in Dar es Salaam, and to provide parameter estimates for HIV prevalence and intracluster correlation coefficients, to inform a subsequent larger study. The larger study was ultimately judged infeasible based on the HIV prevalence measured in this study. We first randomly selected eight bars from a sampling frame listing all licensed premises in Kinondoni district, DSM (one of the three districts in the municipality). We repeatedly sampled without replacement first a page number and then line number from the listing. Our work was a feasibility study for a larger study, and thus no formal power calculation was used to establish sample size. However, our sample of 56 individuals with HIV tests gave us $66 \%$ power to provide $95 \%$ CIs of $\pm 10 \%$ around an expected HIV prevalence estimate of $20 \%$.

The field team visited each bar at a time arranged by telephone with each bar's licensee. After explaining the study first to the bar manager and then to all FBW present, FBW were invited to participate in a computer-assisted personal interview (CAPI), and then complete HIV testing and counselling. Study inclusion criteria were being 18 years or older and working as a FBW at the time of study visit. Between 6 and 12 FBW-depending on the length of each interview-were chosen at random within each bar based on a list drawn up by the bar manager at first bar entry. All interviews were conducted in a three-wheel taxi (bajaji) with closed sides parked close to the bar, to ensure privacy.

The CAPI covered several topics, including: women's sociodemographics; their work history; their sexual history, including past STI diagnoses and HIV testing; their knowledge of HIV prevention modalities; substance use; and 
psychological well-being (depression, post-traumatic stress disorder (PTSD) and generalised social support). For depression, we asked the 9-item Patient Health Questionnaire (PHQ-9) scale, which has previously been used with Tanzanian women living with HIV. ${ }^{41}$ We assessed PTSD using the PTSD-IV screening tool. Generalised social support was measured using a 10-item version of the Duke-University of North Carolina (UNC) Functional Social Support Questionnaire (FSSQ), adapted to include instrumental support and validated for Tanzanian women. ${ }^{42}$ Potential responses to each FSSQ question were: 'as much as I would like' (4); 'less than I would like' (3); 'much less than I would like' (2) and 'never' (1). A mean score $<3$ is considered as 'low social support'.

Respondents were asked if they had ever heard of PrEP or a daily pill to prevent HIV infection. Then, following a brief description of each modality, they were asked how interested they were in taking PrEP as: (1) a daily pill; (2) an injection every 3 months; (3) a pericoital vaginal gel and (4) a monthly vaginal ring. For each PrEP modality, interest was gauged on a five-point scale: very interested; somewhat interested; neutral; somewhat uninterested and very uninterested. Finally, they were asked to rank the four modalities from most to least preferred. All PrEP questions are presented in online supplementary material 1. Questions about PrEP were not asked to those who self-reported having previously tested HIV positive, and due to a coding error were not asked at the first bar visited. Anyone testing positive for HIV and not already linked to care was referred to their clinic of choice.

In this analysis, we provide descriptive statistics for various potential risk and protective factors for HIV acquisition. We then assess bivariate associations between these factors and interest in various modalities of PrEP, using $\chi^{2}$ tests for binary variables and Kruskal-Wallis tests for continuous and ordinal variables. We dichotomised PrEP interest as either positive (very interested or somewhat interested) or not (neutral, somewhat uninterested or very uninterested), in order to evaluate which factors were and were not associated with active interest in PrEP. HIV status was measured based on HIV test result.

Written informed consent was obtained from each participant.

\section{Participant and public involvement}

Neither patients nor public were directly involved in the development, design or recruitment of the study. HIV test results were provided to participants at point of testing; results will not otherwise be disseminated directly to study participants.

\section{RESULTS}

\section{Participant characteristics}

Sixty-six FBW were invited to participate in the study and all agreed (table 1). Most of the women were in their twenties (median age 26, IQR 23-30). Almost all the women $(91 \%)$ were born outside of DSM. FBW had been working as barmaids for a median of 2 years (IQR 4 months to 4 years). Only $9 \%$ FBW planned to continue working as FBW, all but one of whom planned to stop within 2 years. FBW reported a median monthly income of US $\$ 91$ (IQR US\$68-136). Most FBW (85\%) had been pregnant in the past, $44 \%$ reported having had an unintended pregnancy and $39 \%$ a miscarriage or termination. Seventy-one per cent of FBW had a living child at the time of interview (median 1, IQR 1-2).

Psychometric properties for the well-being measures were acceptable: Cronbach's alpha was 0.71 for PHQ-9, 0.71 for the PTSD-IV and 0.85 for FSSQ. Based on standard score summation, $20 \%$ of respondents showed depressive symptoms, while $21 \%$ affirmed 3 or 4 PTSD-IV questions and thus screened positive for possible PTSD, and $58 \%$ had a mean FSSQ score $<3$ and thus had low social support.

Almost all (96\%) of FBW had previously taken an HIV test (median 3 tests in lifetime, IQR 2-5), with 53\% having tested within the past 6 months and $78 \%$ within the past 12. Three women (5\%) had previously tested positive for HIV. Fifty-six FBW (85\%) consented to test for HIV and four of these $(7 \%)$ tested positive; only one had not previously received a positive test result.

\section{HIV acquisition risk factors}

Exactly half of FBW reported ever having had sex with someone in return for money: $20 \%$ only with bar clients; $15 \%$ only with other men and $15 \%$ with both. Of the $35 \%$ FBW reporting sex with bar clients, $74 \%$ reported asking clients to use condoms often or always. A majority (52\%) reported that clients sometimes or often asked not to use condoms, but only $8 \%$ of FBW reported often or always agreeing not to use condoms in situations where they want to use a condom but their clients has asked not to. FBW also reported a median of two non-commercial partners in the past 12 months (IQR 1-3, maximum 8). Sixty-eight per cent of FBW reported having a primary partner, and only $18 \%$ of these women reported using a condom at last sex with this partner. Only $30 \%$ of FBW reported using male or female condoms as a family planning method, while another $24 \%$ reported using pills, injectables or implants. Almost half $(47 \%)$ of respondents believed they were either at great risk of, or certain to become infected with, HIV.

\section{PrEP interest}

Questions about PrEP were asked to 56 women (3 had previously tested HIV positive, 7 were in the first bar visited). Only $5 \%$ of these FBW had ever heard of PrEP; however, $54 \%$ were either somewhat or very interested in a daily pill that protected against HIV infection, and only $16 \%$ were uninterested (figure 1A). When asked about other potential treatment modalities, $79 \%$ of FBW were interested or very interested in long-acting injectable PrEP, 38\% in vaginal gel PrEP and only $11 \%$ in monthly vaginal ring PrEP. Only one women was somewhat or very uninterested in any type of PrEP. Level of interest in daily pill PrEP was statistically significantly correlated 
Table 1 Descriptive statistics for sociodemographic and behavioural risk factors for HIV

\begin{tabular}{|c|c|c|c|c|}
\hline & \multicolumn{2}{|c|}{ All respondents } & \multicolumn{2}{|c|}{ PrEP question respondents } \\
\hline & $\mathbf{N}$ & & $\mathbf{N}$ & \\
\hline Age & 66 & $26(23-30)$ & 56 & $25(23-29)$ \\
\hline Born in Dar es Salaam & 65 & $9 \%$ & 55 & $9 \%$ \\
\hline Years working in bars & 66 & $2(0.4-4)$ & 56 & $1.8(0.4-3)$ \\
\hline Plan to continue bar work & 66 & $11 \%$ & 56 & $9 \%$ \\
\hline Monthly income (US\$) & 62 & $91(68-136)$ & 53 & $91(68-136)$ \\
\hline Ever been pregnant & 66 & $85 \%$ & 56 & $82 \%$ \\
\hline Of whom, ever had undesired pregnancy & 56 & $52 \%$ & 46 & $54 \%$ \\
\hline Of whom, ever had termination or miscarriage & 56 & $46 \%$ & 46 & $46 \%$ \\
\hline Ever had sex with anyone for money & 66 & $50 \%$ & 56 & $54 \%$ \\
\hline Ever had sex with patron for money & 66 & $35 \%$ & 56 & $38 \%$ \\
\hline Of whom, ever had oral sex with patron & 23 & $70 \%$ & 21 & $30 \%$ \\
\hline Of whom, ever had vaginal sex with patron & 23 & $48 \%$ & 21 & $67 \%$ \\
\hline Of whom, how often asks patron to use condom* & 23 & $4(3-4)$ & 21 & $4(4-4)$ \\
\hline Of whom, how often patron asks not to use condom* & 23 & $2(1-3)$ & 21 & $3(2-3)$ \\
\hline Ever had sex with others for money & 66 & $30 \%$ & 21 & $48 \%$ \\
\hline Number of non-client partners in past 12 months & 56 & $2(1-3)$ & 47 & $1(1-3)$ \\
\hline Has a primary partner & 66 & $68 \%$ & 56 & $66 \%$ \\
\hline Of whom, used condom at last sex with primary partner & 44 & $18 \%$ & 37 & $19 \%$ \\
\hline Currently using male condoms for family planning & 66 & $36 \%$ & 56 & $38 \%$ \\
\hline PHQ-9 major depressive symptoms & 66 & $20 \%$ & 56 & $16 \%$ \\
\hline PTSD-IV screen positive & 66 & $21 \%$ & 56 & $23 \%$ \\
\hline Low social support & 66 & $58 \%$ & 56 & $55 \%$ \\
\hline Ever taken an HIV test & 66 & $97 \%$ & 56 & $96 \%$ \\
\hline Number of HIV tests ever taken & 64 & $3(2-5)$ & 54 & $3(2-5)$ \\
\hline Months since last HIV test & 64 & $6(3.5-12)$ & 54 & $6(4-12)$ \\
\hline Willing to complete HCT today & 66 & $85 \%$ & 56 & $86 \%$ \\
\hline
\end{tabular}

Values are counts $(\mathrm{N})$, proportions or medians and IQRs.

*5-point scale; higher values indicate greater frequency.

HCT, HIV counselling and testing; PHQ, Patient Health Questionnaire; PTSD, post-traumatic stress disorder.

with interest in long-acting injectable $\operatorname{PrEP}(\rho=0.40$ , $\mathrm{p}=0.003)$, but not with either vaginal modality. When asked to rank the four modalities, the most preferred method was long-acting injectable PrEP, although $82 \%$ of women ranked daily pill PrEP as either their first or second preference (figure 1B). Restricting our sample to all respondents with at least 'neutral' $(96 \%)$ or at least 'somewhat interested' (86\%) responses for at least one PrEP modality did not change these patterns.

\section{Correlates of PrEP interest}

Associations between interest in each PrEP modality and the range of HIV risk factors are presented in table 2. There was no significant difference in interest level (very/somewhat interested vs neutral or somewhat/very uninterested) in daily- pill PrEP for those who did/did not report any sex for money ( $60 \%$ vs $46 \%, \mathrm{p}=0.30)$. This pattern was similar for those who did/did not report sex for money with bar clients (62\% vs $49 \%, \mathrm{p}=0.33$ ) and those who did/did not report sex for money with others (59\% vs $51 \%, \mathrm{p}=0.60)$. Interest in long-acting injectable PrEP was similarly not significantly associated with having had sex in return for money (any sex for money: $80 \%$ vs $77 \%$, $\mathrm{p}=0.78$; sex for money with bar clients: $86 \%$ vs $74 \%$, $\mathrm{p}=0.31$; sex for money with non-bar clients: $76 \%$ vs $79 \%$, $\mathrm{p}=0.80$ ). The only sociodemographic or behavioural factor associated with significantly higher interest in daily pill PrEP was a history of miscarriage or termination ( $61 \%$ vs $39 \%, \mathrm{p}=0.04)$. The only factor associated with significantly higher interest in long-acting injectable PrEP was number of non-client partners in the past 12 months (interest: median 2, IQR 1-3; no interest: median 1, IQR $1-1 ; p=0.03)$. Willingness to consent for an HIV test was not significantly associated with interest in daily pill PrEP ( $54 \%$ vs $50 \%, \mathrm{p}=0.83$ ). 
A

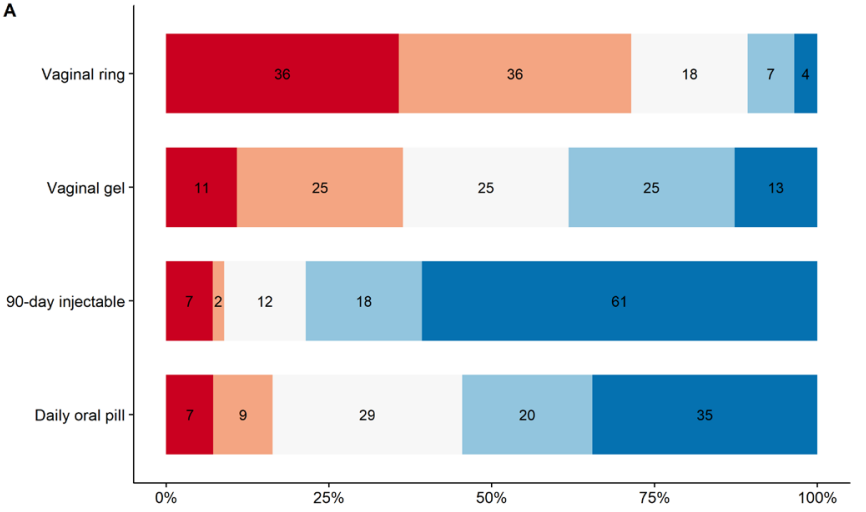

Very uninterested Somewhat interested Neutral $\quad$ Somewhat interested $\quad$ Very interested

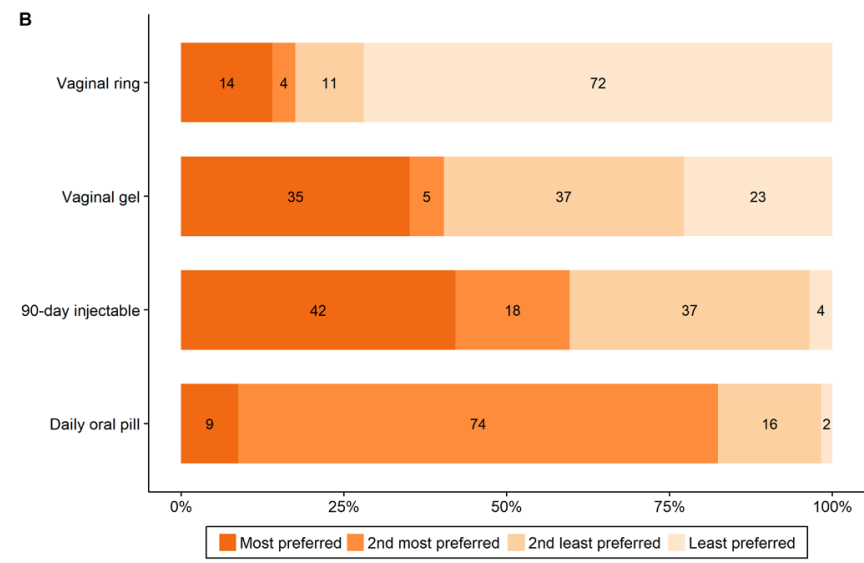

Figure 1 Female bar worker interest in, and ordered preferences for, various pre-exposure prophylaxis (PrEP) modalities. (A) Level of interest in each PrEP modality. (B) Ordered preference for each PrEP modality. Numbers in figures are percentages of all respondents.

\section{DISCUSSION}

In a random sample of 66 FBW from bars in DSM, HIV prevalence was low (similar to the $7 \%$ prevalence for 25-29year old women nationally, and 8\% for 15-49year old women in DSM, in 2011-2012, the most recent nationally representative survey ${ }^{43}$ ). However, risk factors for HIV acquisition were substantial-including multiple partners, moderate-to-low condom use and substantial levels of sex for money. The proportion of FBW reporting sex for money was similar to earlier quantitative studies. ${ }^{78}$

Awareness of PrEP for HIV prevention was very low but interest in PrEP, particularly for daily pills and long-acting injectables, was high. Both these modalities are likely to be recognisable to women in Tanzania since family planning options have similar modes of delivery, for example, daily contraceptive pills, injectable Depo-Provera and implanted Nur-Isterate. Greater interest in long-acting injectables may also reflect the difficulties of taking daily pills for these working women, and of applying gels prior to sex when timing of sex acts is unpredictable and sometimes not chosen by them. These findings thus resonate with those of earlier work in other SSA settings with FSW, which found limited retention on daily pill-based PrEP. ${ }^{23-25}$
While many of differences in PrEP interest were not significant in this small sample (and none remain significant if we adjust for multiple testing using the Holm-Bonferroni or any other method), respondents who reported having sex for money (either with bar clients or others), those who had had a miscarriage or abortion and those with more non-client partners all reported greater interest in PrEP. This pattern of findings, if reproduced in other data, would suggest that those FBW with a higher risk profile for sexually transmitted infections have a rationally greater interest in PrEP. It was also notable that PrEP interest was similar for those having sex either with bar clients or with others; if efforts are made to determine which FBW are having sex for money, inquiries should not be limited to bar patrons.

This study highlights that FBW in Dar are at substantial risk for HIV acquisition, that many are aware that they are at substantial risk and following discussion many are interested PrEP. However, this is only the first stage of the PrEP care continuum, ${ }^{44}$ FBW will additionally need assistance in accessing PrEP and remaining in care. Both of these stages are likely to be hampered by the stigma and fluidity of life situation that working as an FBW can bring.

While no PrEP is currently available to Tanzanian women, daily pill PrEP demonstration trials will begin in key Tanzanian populations in 2018 and long-acting injectable PrEP has reached phase-III trials elsewhere through HPTN-084. ${ }^{45}$ Successful PrEP strategies for FBW will require tailored PrEP programming for such women, mostly likely including clinical care provided outside standard clinics. One important option here might be workplace-based service provision-since the bar location forms a multiyear basis for work for the majority of respondents.

\section{Strengths and limitations}

This study provides the first insight into the HIV serostatus and PrEP interest of FBW in DSM. While the sample in this study is small, it was a random sample drawn from a full enumeration of all licensed premises $(n>2500)$ in Kinondoni district, an area with a population of over 1750000 inhabitants in 2012, ${ }^{46}$ and then a full enumeration of all FBW working in each bar at the time of first visit. Nevertheless, it is possible that the sample of women drawn differs on some characteristics from other FBW in Kinondoni. Furthermore, our small sample size means that we cannot rule out some substantial but not significant associations in fact reflecting true associations that this study lacks the power to confirm. Further analysis with additional FBW would allow the separation of truly null associations from underpowered analyses. Similarly, we are not able to conduct multivariable analysis in this dataset, something that would be important in follow-up work.

Caution is needed in generalising beyond Kinondoni to the rest of DSM, as well as to other areas of Tanzania and East Africa. However, even should the results only be applicable within Kinondoni or DSM, our results 
Table 2 Associations between sociodemographic and behavioural factors and interest in pre-exposure prophylaxis modalities

\begin{tabular}{|c|c|c|c|c|c|c|c|c|}
\hline & \multicolumn{2}{|l|}{ Daily pill } & \multicolumn{2}{|c|}{90 day injectable } & \multicolumn{2}{|l|}{ Vaginal gel } & \multicolumn{2}{|l|}{ Vaginal ring } \\
\hline & No & Yes & No & Yes & No & Yes & No & Yes \\
\hline $\begin{array}{l}\text { Very/somewhat } \\
\text { interested in modality }\end{array}$ & 30 & 26 & 12 & 44 & 35 & 21 & 50 & 6 \\
\hline Age & $25(23-30)$ & 25 (23-28) & $23(22-28.5)$ & 25 (23-29) & $25(22-28)$ & $25(23-30)$ & 25 (22-29) & $27(24-27)$ \\
\hline Born in Dar es Salaam & $8 \%$ & $10 \%$ & $8 \%$ & $9 \%$ & $9 \%$ & $10 \%$ & $8 \%$ & $17 \%$ \\
\hline Years working in bars & $1.8(0.4-3)$ & $1.8(0.3-3)$ & $1.5(0.2-2.5)$ & $1.8(0.5-3)$ & $1.5(0.5-3)$ & $2(0.25-6)$ & $1.5(0.4-3)$ & $2(2-3)$ \\
\hline Monthly income (US\$) & $91(68-136)$ & $91(57-148)$ & $91(68-136)$ & $91(68-159)$ & $102(80-136)$ & $91(55-182)$ & $91(68-159)$ & $91(91-91)$ \\
\hline Ever been pregnant & $88 \%$ & $77 \%$ & $83 \%$ & $82 \%$ & $80 \%$ & $86 \%$ & $82 \%$ & $83 \%$ \\
\hline $\begin{array}{l}\text { Of whom, ever had } \\
\text { undesired pregnancy }\end{array}$ & $48 \%$ & $61 \%$ & $50 \%$ & $56 \%$ & $64 \%$ & $39 \%$ & $56 \%$ & $40 \%$ \\
\hline $\begin{array}{l}\text { Ever had sex with patron } \\
\text { for money }\end{array}$ & $31 \%$ & $43 \%$ & $25 \%$ & $41 \%$ & $40 \%$ & $33 \%$ & $38 \%$ & $33 \%$ \\
\hline $\begin{array}{l}\text { Of whom, ever had oral } \\
\text { sex with patron }\end{array}$ & $27 \%$ & $33 \%$ & $33 \%$ & $30 \%$ & $31 \%$ & $29 \%$ & $34 \%$ & $0 \%$ \\
\hline $\begin{array}{l}\text { Of whom, ever had } \\
\text { vaginal sex with patron }\end{array}$ & $75 \%$ & $62 \%$ & $100 \%$ & $61 \%$ & $64 \%$ & $71 \%$ & $63 \%$ & $100 \%$ \\
\hline $\begin{array}{l}\text { Of whom, how often } \\
\text { asks patron to use } \\
\text { condom* }\end{array}$ & $4(4-4)$ & $4(3-4)$ & $4(4-4)$ & $4(3-4)$ & $4(2-4)$ & $4(4-4)$ & $4(4-4)$ & $3.5(3-4)$ \\
\hline $\begin{array}{l}\text { Of whom, how often } \\
\text { patron asks not to use } \\
\text { condom* }\end{array}$ & $1.5(1-2.5)$ & $2(2-3)$ & $2(1-2)$ & $2(1-3)$ & $2(1-3)$ & $2(1-2)$ & $2(1-3)$ & $2(1-3)$ \\
\hline $\begin{array}{l}\text { Of whom, used condom } \\
\text { at last sex with primary } \\
\text { partner }\end{array}$ & $11 \%$ & $26 \%$ & $11 \%$ & $21 \%$ & $12 \%$ & $36 \%$ & $16 \%$ & $33 \%$ \\
\hline $\begin{array}{l}\text { Currently using male } \\
\text { condoms for family } \\
\text { planning }\end{array}$ & $40 \%$ & $53 \%$ & $40 \%$ & $48 \%$ & $38 \%$ & $60 \%$ & $43 \%$ & $75 \%$ \\
\hline $\begin{array}{l}\text { PHQ-9 major depressive } \\
\text { symptoms }\end{array}$ & $15 \%$ & $27 \%$ & $8 \%$ & $25 \%$ & $17 \%$ & $29 \%$ & $24 \%$ & $0 \%$ \\
\hline PTSD-IV screen positive & $15 \%$ & $30 \%$ & $8 \%$ & $27 \%$ & $20 \%$ & $29 \%$ & $24 \%$ & $17 \%$ \\
\hline Low social support & $50 \%$ & $60 \%$ & $58 \%$ & $55 \%$ & $54 \%$ & $57 \%$ & $58 \%$ & $33 \%$ \\
\hline Ever taken an HIV test & $100 \%$ & $93 \%$ & $100 \%$ & $95 \%$ & $97 \%$ & $95 \%$ & $96 \%$ & $100 \%$ \\
\hline $\begin{array}{l}\text { Number of HIV tests } \\
\text { ever taken }\end{array}$ & $3(2-5)$ & $3(2-5)$ & $3(1.5-5.5)$ & $3(2-5)$ & $3(2-5)$ & $3(2-4)$ & $3(2-5)$ & $3.5(1-5)$ \\
\hline $\begin{array}{l}\text { Months since last HIV } \\
\text { test }\end{array}$ & $5(4-10)$ & $7(4-13.5)$ & $5(3.5-9)$ & $7(4-12)$ & $6.5(5-15)$ & $5.5(3.5-7)$ & $6(4-12)$ & $8.5(4-11)$ \\
\hline $\begin{array}{l}\text { Willing to complete HCT } \\
\text { today }\end{array}$ & $25(23-30)$ & 25 (23-28) & $23(22-28.5)$ & 25 (23-29) & 25 (22-28) & $25(23-30)$ & 25 (22-29) & $27(24-27)$ \\
\hline
\end{tabular}

Values are counts (interest in modality row), proportions or medians and IQRs.

The two significant differences (at $\alpha=0.05$ ) between variables based on a $\chi_{1}^{2}$ test for binary factors and Kruskal-Wallis tests for continuous and ordinal factors are shown in bold.

*5-point scale; higher values indicate greater frequency.

FP, family planning; HCT, HIV counselling and testing; PHQ, Patient Health Questionnaire; PTSD, post-traumatic stress disorder. 
suggest that a very large number of FBW in this region are at risk of HIV acquisition and local interventions may be warranted. Additionally, since many of the questions asked were sensitive ones, and the responses self-reported through face-to-face interviews, FBW may have under-reported some risk behaviours. The potential for social desirability bias to affect questions about PrEP was lessened by the very low baseline awareness of this HIV prevention option.

\section{CONCLUSIONS}

Based on these initial data, FBW are likely to be a key population for HIV prevention efforts, including PrEP, to protect both themselves and their partners from acquiring HIV. PrEP seems acceptable to this sample of FBW-who commonly engaged in unprotected transactional sex with clients, but planned to discontinue sex work in the near future.

This study also provided evidence of the feasibility of contacting FBW at their workplaces. Nevertheless, further information is needed on both the best design for delivering PrEP and supporting HIV-related health services to this population and the effectiveness of different PrEP models in attracting FBW to PrEP and ensuring continued PrEP utilisation throughout periods of high HIV acquisition risk.

\author{
Author affiliations \\ ${ }^{1}$ Institute for Global Health, University College London, London, UK \\ ${ }^{2}$ Department of Epidemiology, Harvard T. H. Chan School of Public Health, Boston, \\ Massachusetts, USA \\ ${ }^{3}$ Africa Health Research Institute, KwaZulu-Natal, South Africa \\ ${ }^{4}$ Management and Development for Health, Dar es Salaam, Tanzania \\ ${ }^{5}$ International Clinical Research Center, University of Washington, Seattle, \\ Washington, USA \\ ${ }^{6}$ Heidelberg Institute of Global Health, Medical Faculty and University Hospital, \\ Heidelberg University, Heidelberg, Germany \\ ${ }^{7}$ Francis I Proctor Foundation, University of California San Francisco, San Francisco, \\ California, USA \\ ${ }^{8}$ Departments of Ophthalmology \& Epidemiology and Biostatistics, University of \\ California San Francisco, San Francisco, California, USA \\ ${ }^{9}$ Department of Global Health and Population, Harvard T.H. Chan School of Public \\ Health, Boston, Massachusetts, United States \\ ${ }^{10}$ Department of Biostatistics, Harvard T.H. Chan School of Public Health, Boston, \\ Massachusetts, USA \\ ${ }^{11}$ Department of Nutrition, Harvard T.H. Chan School of Public Health, Boston, \\ Massachusetts, USA \\ ${ }^{12}$ Center for Methods in Implementation and Prevention Science, Yale School of \\ Public Health, New Haven, Connecticut, USA
}

Acknowledgements The authors thank the Kinondoni District Medical Officer, bar owners, bar managers and barmaids for their assistance conducting this study.

Contributors DS and TB conceptualised the study and contributed to the study design. GH contributed to study design, conducted the analyses, summarised the results in tables and figures and wrote the first draft of the paper. AM, KFO, IM, PD, $\mathrm{NU}$ and EM contributed substantially to data acquisition. DB and CEO contributed to the study design and interpretation. All authors contributed to the study design, data interpretation and revisions to the text, and approved the final text and agreed to be accountable for the work.

Funding This study was supported by the National Institute on Aging (grant R01-Al112339). KF0 was supported in part by the National Institute of Allergy and Infectious Disease T32- Al007535 (PI Seage). CE0 was supported in part by the
National Institute on Drug Abuse T32- DA013911 (PI Flanigan) and the National Institute of Mental Health R25-MH083620 (PI Nunn). TB was supported by the Alexander von Humboldt Foundation through the Alexander von Humboldt professor award, which is funded by the German Federal Ministry of Education and Research; the Wellcome Trust; the European Union, the European Commission; the Clinton Health Access Initiative; and the National Institutes of Health through the National Institute of Child Health and Human Development (R01-HD084233), the National Institute on Aging (P01- AG041710), the National Institute of Allergy and Infectious Diseases (R01-Al124389) and the Fogarty International Center (D43-TW009775).

Disclaimer The funders had no role in study design, data collection and analysis, decision to publish, or preparation of the manuscript.

Competing interests None declared.

Patient consent for publication Not required.

Ethics approval The study received ethical approval from Harvard T.H. Chan School of Public Health and the Tanzanian National Institute for Medical Research.

Provenance and peer review Not commissioned; externally peer reviewed.

Data sharing statement All unpublished data related to this research project are available with the authors and can be requested by emailing to g.harling@ucl.ac.uk.

Open access This is an open access article distributed in accordance with the Creative Commons Attribution Non Commercial (CC BY-NC 4.0) license, which permits others to distribute, remix, adapt, build upon this work non-commercially, and license their derivative works on different terms, provided the original work is properly cited, appropriate credit is given, any changes made indicated, and the use is non-commercial. See: http://creativecommons.org/licenses/by-nc/4.0/.

\section{REFERENCES}

1. Baral S, Beyrer C, Muessig K, et al. Burden of HIV among female sex workers in low-income and middle-income countries: a systematic review and meta-analysis. Lancet Infect Dis 2012;12:538-49.

2. Gouws E, Cuchi P, International Collaboration on Estimating HIV Incidence by Modes of Transmission. Focusing the HIV response through estimating the major modes of HIV transmission: a multicountry analysis. Sex Transm Infect 2012;88(Suppl 2):i76-i85.

3. Shannon K, Strathdee SA, Goldenberg SM, et al. Global epidemiology of HIV among female sex workers: influence of structural determinants. Lancet 2015;385:55-71.

4. Harcourt C, Donovan B. The many faces of sex work. Sex Transm Infect 2005;81:201-6.

5. Sori AT. Poverty, sexual experience and HIV vulnerability risks: evidence from Addis Ababa, Ethiopia. J Biosoc Sci 2012;44:677-701.

6. Rosenheck R, Ngilangwa D, Manongi R, et al. Treatment-seeking behavior for sexually transmitted infections in a high-risk population. AIDS Care 2010;22:1350-8.

7. Ao TT, Sam NE, Masenga EJ, et al. Human immunodeficiency virus type 1 among bar and hotel workers in northern Tanzania: the role of alcohol, sexual behavior, and herpes simplex virus type 2. Sex Transm Dis 2006;33:163-9.

8. Riedner G, Rusizoka M, Hoffmann O, et al. Baseline survey of sexually transmitted infections in a cohort of female bar workers in Mbeya Region, Tanzania. Sex Transm Infect 2003;79:382-7.

9. van Blerk L. Negotiating boundaries: the sex work identities of 'bar girls' in Nazareth, Ethiopia. Gender, Place \& Culture 2011;18:217-33.

10. Kerrigan D, Mbwambo J, Likindikoki S, et al. Project shikamana: baseline findings from a community empowerment-based combination hiv prevention trial among female sex workers in Iringa, Tanzania. J Acquir Immune Defic Syndr 2017;74(Suppl 1):S60.

11. Beckham S. "Like any other woman"? Pregnancy, motherhood, and hiv among sex workers in southern tanzania. Johns Hopkins University 2013.

12. Talle A. Bar workers at the border. In: Klepp K-I, Biswalo PM, Talle A, eds. Young people at risk: fighting AIDS in northern Tanzania. Oslo, Norway: Scandinavian University Press, 1995:18-30.

13. Poverty VBL. migration and sex work: youth transitions in Ethiopia. Area 2008;40:245-53.

14. National Bureau of Statistics (NBS) [Tanzania]. Tanzania integrated labour force survey 2014. Dar es Salaam: NBS, 2014.

15. Akarro RR. Some factors associated with condom use among bar maids in Tanzania. J Biosoc Sci 2009;41:125-37.

16. Bekker LG, Johnson L, Cowan F, et al. Combination HIV prevention for female sex workers: what is the evidence? Lancet 2015;385:72-87. 
17. Iskarpatyoti BS, Lebov J, Hart L, et al. Evaluations of structural interventions for HIV prevention: a review of approaches and methods. AIDS Behav 2018;22:1253-64.

18. Baeten JM, Donnell D, Ndase P, et al. Antiretroviral prophylaxis for HIV prevention in heterosexual men and women. N Engl J Med 2012;367:399-410.

19. Thigpen MC, Kebaabetswe PM, Paxton LA, et al. Antiretroviral preexposure prophylaxis for heterosexual HIV transmission in Botswana. N Engl J Med 2012;367:423-34.

20. AVAC. HIV prevention research \& development database. 2016 http://www.avac.org/pxrd (accessed 22 Aug 2017).

21. Cowan FM, Delany-Moretlwe S, Sanders EJ, et al. PrEP implementation research in Africa: what is new? J Int AIDS Soc 2016;19(7(Suppl 6)):21101.

22. van der Straten A, Van Damme L, Haberer JE, et al. Unraveling the divergent results of pre-exposure prophylaxis trials for HIV prevention. AIDS 2012;26:F13-F19.

23. Eakle R, Gomez GB, Mbogua J, et al. Treatment and prevention for female sex workers in south africa: first-year results for the taps demonstration project. HIV research for prevention. Chicago, IL 2016.

24. Kyongo J, Kiragu M, Nduta S, et al. Oral PrEP for HIV prevention: early lessons from a prep demonstration project in Kenya. HIV Research for Prevention. Chicago, IL 2016.

25. Cowan FM, Davey C, Fearon E, et al. Targeted combination prevention to support female sex workers in Zimbabwe accessing and adhering to antiretrovirals for treatment and prevention of HIV (SAPPH-IRe): a cluster-randomised trial. Lancet HIV 2018;5:e417-e426.

26. Molina JM, Capitant C, Spire B, et al. on-demand preexposure prophylaxis in men at high risk for HIV-1 infection. $N$ Engl J Med 2015;373:2237-46.

27. Landovitz RJ, Kofron R, McCauley M. The promise and pitfalls of long-acting injectable agents for HIV prevention. Curr Opin HIV AIDS 2016;11:122-8

28. Margolis DA, Gonzalez-Garcia J, Stellbrink HJ, et al. Long-acting intramuscular cabotegravir and rilpivirine in adults with HIV-1 infection (LATTE-2): 96-week results of a randomised, open-label, phase 2b, non-inferiority trial. Lancet 2017;390:1499-510.

29. Abdool Karim Q, Abdool Karim SS, Frohlich JA, et al. Effectiveness and safety of tenofovir gel, an antiretroviral microbicide, for the prevention of HIV infection in women. Science 2010;329:1168-74.

30. Baeten JM, Palanee-Phillips T, Brown ER, et al. Use of a vaginal ring containing dapivirine for hiv-1 prevention in women. N Engl J Med 2016;375:2121-32

31. World Health Organization. Consolidated guidelines on the use of antiretroviral drugs for treating and preventing HIV infection: recommendations for a public health approach. Geneva: World Health Organization, 2016.
32. Beyrer C, Crago AL, Bekker LG, et al. An action agenda for HIV and sex workers. Lancet 2015;385:287-301.

33. South African National AIDS Council (SANAC). The South African National Sex Worker HIV Plan 2016-2019. Pretoria, South Africa: SANAC, 2016.

34. National AIDS \& STI Control Programme (NASCOP). Framework for the implementation of pre-exposure prophylaxis of HIV in Kenya. Nairobi, Kenya: NASCOP, 2017.

35. Botswana Ministry of Health. Handbook of the Botswana 2016 integrated HIV clinical care guidelines. Gabarone, Bostwana: Botswana Ministry of Health, 2016.

36. Koechlin FM, Fonner VA, Dalglish SL, et al. Values and preferences on the use of oral pre-exposure prophylaxis (prep) for hiv prevention among multiple populations: a systematic review of the literature. AIDS Behav 2017;21:1325-35.

37. Van der Elst EM, Mbogua J, Operario D, et al. High acceptability of HIV pre-exposure prophylaxis but challenges in adherence and use: qualitative insights from a phase I trial of intermittent and daily PrEP in at-risk populations in Kenya. AIDS Behav 2013;17:2162-72.

38. Population Council. Adolescent girls and young women's perceptions of oral pre-exposure prophylaxis introduction in Tanzania: findings from implementation science research". DREAMS Tanzania Results Brief 3. Washington, DC: Population Council, 2017.

39. Lees S, Scorgie F, Khoza N, et al. Understanding motives for initiating PrEP amongst adolescent girls and young women (AGYW) in South Africa and Tanzania. AIDS 2018. Amsterdam, the Netherlands, 2018.

40. Pilgrim N, Jani N, Mathur S, et al. Provider perspectives on PrEP for adolescent girls and young women in Tanzania: The role of provider biases and quality of care. PLoS One 2018;13:e0196280.

41. Belenky NM, Cole SR, Pence BW, et al. Depressive symptoms, HIV medication adherence, and HIV clinical outcomes in Tanzania: a prospective, observational study. PLoS One 2014;9:e95469.

42. Antelman G, Smith Fawzi MC, Kaaya S, et al. Predictors of HIV-1 serostatus disclosure: a prospective study among HIV-infected pregnant women in Dar es Salaam, Tanzania. AIDS 2001;15:1865-74.

43. Tanzania Commission for AIDS (TACAIDS), Zanzibar AIDS Commission (ZAC), National Bureau of Statistics (NBS), Office of the Chief Government Statistician (OCGS), ICF International. Tanzania HIVIAIDS and Malaria Indicator Survey 2011-12. Dar es Salaam, Tanzania: TACAIDS, ZAC, NBS, OCGS, and ICF International, 2013.

44. Nunn AS, Brinkley-Rubinstein L, Oldenburg CE, et al. Defining the HIV pre-exposure prophylaxis care continuum. AIDS 2017;31:731-4

45. NIH. NIH launches first large trial of a long-acting injectable drug for hiv prevention: study to test efficacy, safety of injectable cabotegravir compared to daily oral PrEP. 20. 2016 https://www.niaid.nih.gov/ news-events/nih-launches-first-large-trial-long-acting-injectabledrug-hiv-prevention.

46. National Bureau of Statistics, Office of Chief Government Statistician. 2012 population and housing census: population distribution by administrative areas. Dar es Salaam: National Bureau of Statistics, 2013. 